\title{
Hydraulic Performance of Concrete Block Pavement under High Rainfall Intensities
}

\author{
Laksni Sedyowati ${ }^{1}$, Eko Indah Susanti ${ }^{1}$ \\ ${ }^{1}$ Department of Civil Engineering, University of Merdeka Malang, Malang, 65146, \\ Indonesia \\ laksni.sedyowati@unmer.ac.id
}

Received 15-11-2018; revised 10-01-2019; accepted 04-03-2019

\begin{abstract}
High rainfall intensity will generate different response on the concrete block pavement (CBP) performance. A study found that larger openings of CBP did not lead more water penetrated. In other study, larger openings can lead greater decrease in runoff velocity. The correlation between the openings, water penetration and runoff velocity has remained unclear. In this study, we investigated hydraulic performance of CBP as an impact of surface roughness condition, under high rainfall intensities, saturated sub-base layer, and various slope surfaces. We conducted experiment using a $2 \mathrm{~m}$ by $6 \mathrm{~m}$ of rectangular CBP layer with herringbone $90^{\circ}$ and basket-weave pattern. We used a modified dye tracing method in view to monitor the surface flow velocity under various high rainfall intensities. The results showed that hydraulic performance of surface runoff in the CBP layer was more influenced by the surface roughness condition. The roughness condition was very sensitive to the change in surface configuration of the CBP. The relationship between rainfall intensity, surface slope and roughness number followed polynomial functions. A further study is required to investigate the appropriate quality of CBPs, which have high durability applied over a steep slope surface and under high rainfall intensities.
\end{abstract}

Keywords: Low impact development, sustainable urban drainage system, source control, storm water management, paving blocks, roughness coefficient

\section{Introduction}

The use of concrete block pavement (CBP) has many advantages, such as able to penetrate the rainwater into the blocks, easy in installing, and has aesthetics value. To date, the usage of CBP has been so vary and widely spread. People used the CBP as road, driveway, park, carpark, sidewalk, etc. However, CBP performance in penetrating water has some limitations. It can be effective under some conditions, as follows: 1) the infiltration rate of the sub-base is more than the rainfall intensity [3]; 2) the sub-base has not reached saturated condition; and 3) there is no clogging. Unfortunately, the CBP performance under adverse conditions did not been properly investigated. High rainfall intensity will generate different response on the CBP performance. There will be much water flowing on the CBP surface as runoff, because the infiltration rate is less than the rainfall intensity. More runoff will occur when the sub-base reached saturated condition. Water flows over the CBP surface passing the gap between pavers. 
There have been some researches on the effects of CBP openings on surface runoff discharge and velocity. A study found that larger openings did not lead more water penetrated [1]. Contrastingly, in other study larger openings can lead greater decrease in runoff velocity when the rainfall intensity and the slope surface were getting large [2]. Although more water was flowing over the surface, the runoff velocity will decrease with the increase of rainfall intensity and surface slope. Therefore, there is no general conclusion about the correlation between the openings, water penetration and runoff velocity.

However, a study conducted by Pagliara [4] on a flume by $7.5 \mathrm{~m}$ long, 0.35 wide and $0.60 \mathrm{~m}$ deep, with three kinds of bed material diameter $\left(\mathrm{d}_{50}\right)$ consisted of $11 \mathrm{~mm}, 20 \mathrm{~mm}$ and $75 \mathrm{~mm}$ can be used as comparison. There were spaces between the stones. Those stones and its spaces, particularly for the largest stone, had similarity with the gap between pavers on the CBP that used in this study. Therefore, the configuration of paving blocks surface, that was the combination of the flat surface and the gaps, can produce a roughness factor that can retard the runoff velocity [2]. The virtual bed level, the flow through the rip rap, and the friction factor of the channel wall were also considered [4]. The study concluded that there was an increase in the friction factor with the increase in the slope for the same water depth and the area of boulders cover. The study also indicated that the increase in water depth could lead the decrease in influence of boulders in friction factor. The increase in surface slope can lead the increase of friction factor. The runoff velocity will decrease with an increase in friction factor. Therefore, the increase in surface slope will lead the decrease in runoff velocity.

There have been some researches on the relationship between surface roughness and the runoff velocity. Surface roughness is one of major factor that influencing runoff velocity. "Effective" roughness coefficient was actually generated from the effects of raindrop detachment, channelization of flow, obstacles (such as litter, crop ridges, rocks, and roughness from tillage), frictional drag over the surface, and erosion and sediment transport [5]. Darboux has investigated the role of surface roughness in generating surface runoff [6]. Experiment was conducted in a laboratory scale of a $2.4 \mathrm{~m}$ x $2.4 \mathrm{~m}$ soil box. The results indicated that a major effect on runoff generation could be resulted from a small modification of micro-topographic structure. All experiments indicated that there was a linear relationship between topographic correlation length and depression storage capacity. According to a study conducted by Eitel [7], a surface topography mapped at the sub-cm level was able to generate surface roughness. The scale of the surface roughness - erosion relationship and the regression model parameters were major factors in determining the strength of the relationship between surface roughness and erosion. Effects of surface roughness on overland flow erosion process and advance hydrologic and erosion model parameters development were investigated using terrestrial laser scanning (TLS). The decrease in the strength of the erosion-surface roughness relationship was an effect of removing the slope factor.

An experiment conducted at a flume in the condition of high rainfall intensity and low soil rock fragment cover resulted that flow discharge was delayed slightly by the rock fragments [8]. The presence of the rock fragments led to the increase of infiltration rate. Greater coverage of rock fragment and lower rainfall intensity increased the time-to-runoff. Thus, the results indicated that with low rainfall intensity with significant rock fragment coverage, the surface soil saturation and the steady-state flow achievement take longer than for the case of no rock fragment coverage. The rock fragments were detentions for the overland flow and increasing the average of flow path length, causing to an increase in the time-to-runoff. Although at present National Land Cover Dataset (NLCD) land cover data may be the best practice for parameterizing surface runoff, however, it is inadequate. In terms of roughness parameter modelling, it would be better to use the physical structure or configuration of the terrain and the obstacles lying on it as the basic [9]. A study investigated four empirical models of roughness condition [10]. The models consisted of Darcy-Weisbach, Lawrence, Manning with constant roughness coefficient, and Manning with water depth dependent roughness coefficient. The fourth's model presented the best result comparing with the measured data on a sandy soil plot $10-\mathrm{m}$ by $4-\mathrm{m}$ with rainfall simulation. Thus, roughness coefficient was flow-dependent. A hilly terrain considerably affected the roughness measures on a natural bare soil surface [11]. However, infiltration rate did not significantly influence the flow velocity. There was a limited effect 
of depression storage. This result was in line with the study conducted by Mügler [10]. This research also concluded that overland flow resistance depended on water depth. The flow resistance decreased with an increase in water depth.

The objectives of this study were to investigate the hydraulic performance of CBP indicated by surface roughness condition on CBP surface, the effect of high rainfall intensity and surface slope on roughness condition, and the best performance of CBP on generating the roughness number. The roughness condition was observed under high rainfall intensity, saturated sub-base layer, and various slope surfaces with considering the micro-topography formed by the gap and the pattern of paving blocks arrangement.

\section{Material and Methods}

\subsection{Study site}

Experiments were conducted in a $179 \mathrm{~m}^{2}$ bare land located on a residential area, namely Taman Sulfat Housing, Malang City, East Java Province, Indonesia. An experimental apparatus by $2 \mathrm{~m}$ x $6 \mathrm{~m}$ was built on the area. The apparatus consisted of a paving block test plot and a 5-sprinkler rainfall simulator (Figure. 1). Height of the apparatus at the centre of length was $1.5 \mathrm{~m}$, to accommodate surface slope variability up to $20 \%$. The apparatus was constructed from CNP 15 profile steel in the side and $10 \mathrm{~mm}$ steel plat in the bottom. The test plot and the apparatus had same size. Supply water to rainfall simulator was provided by a pipe-reservoir-pump system. The source of water was taken from freshwater supply agency (PDAM). The pump could produce a pressure up to $1.8 \mathrm{kgf} / \mathrm{cm} 2$ and flow discharge of $10-18 \mathrm{~L} / \mathrm{min}$ to produce rainfall intensity up to $80 \mathrm{~mm} / \mathrm{hr}$.

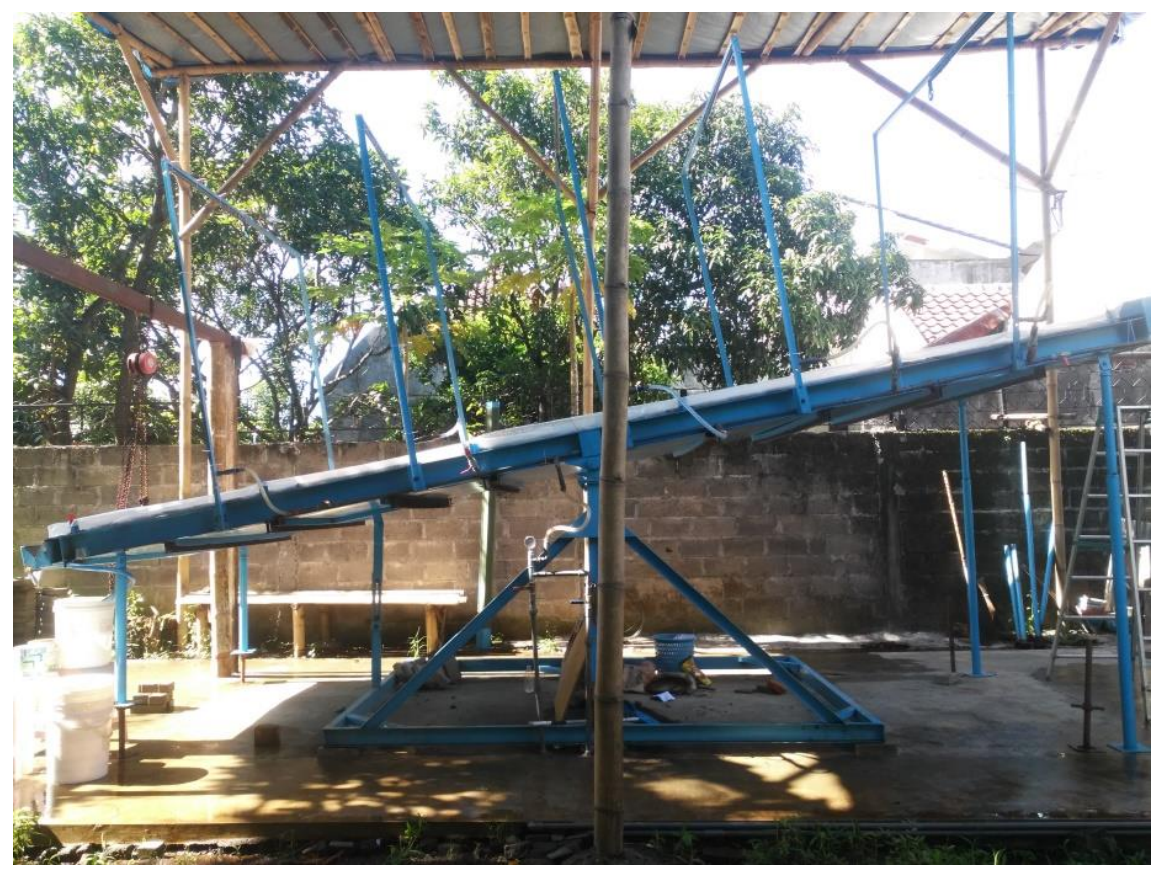

Figure 1. Experimental apparatus with CBP test plot and 5-sprinkler rainfall simulator.

\subsection{Field data measurements and analysis}

Measurements and analysis of observational data was preceded by some activities: 1) installation of the test plot and the rainfall simulator on the experimental apparatus; 2) preparation of flow measurement devices; 3) determination of the study design that included the variability of the 
treatment; 4) Selection of travel time method that used for roughness coefficient analysis on CBP surfaces.

2.2.1. Test plot and rainfall simulator installation. The test plot consisted of four kinds of CBP layers that observed one by one. The layers comprised rectangular CBP $90^{\circ}$-herringbone pattern (pav1), rectangular CBP basket-weave pattern (pav2), tri-hexagonal CBP (pav3), and hexagonal hollow CBP sand filled (pav4). To obtain a water saturation condition in the experimental process, the CBP layer was laid on an impermeable layer. This condition was required in generating an overland flow on the CBP surface. To drain the water that penetrated into the CBPs, there was a hole of $5 \mathrm{~cm}$ diameter at the bottom of the plot. The rainfall simulator was designed to provide uniform rainfall with a simple technology. The technology was easy to construct, using local materials and manually operated (Figure 2). The sprinklers used were butterfly type with specification pressure: 2.0-3.0 bar, flux:40$120 \mathrm{~L} / \mathrm{h}$, range:4-8 m, and save water (Figure 3). It was widely used for irrigation sprinkler and garden watering system. The frames of pipelines and sprinklers were designed such that they can adjust to the changes in slope of the test plot. It also can be moved depend on the space need for rainfall observation (Figure 4).

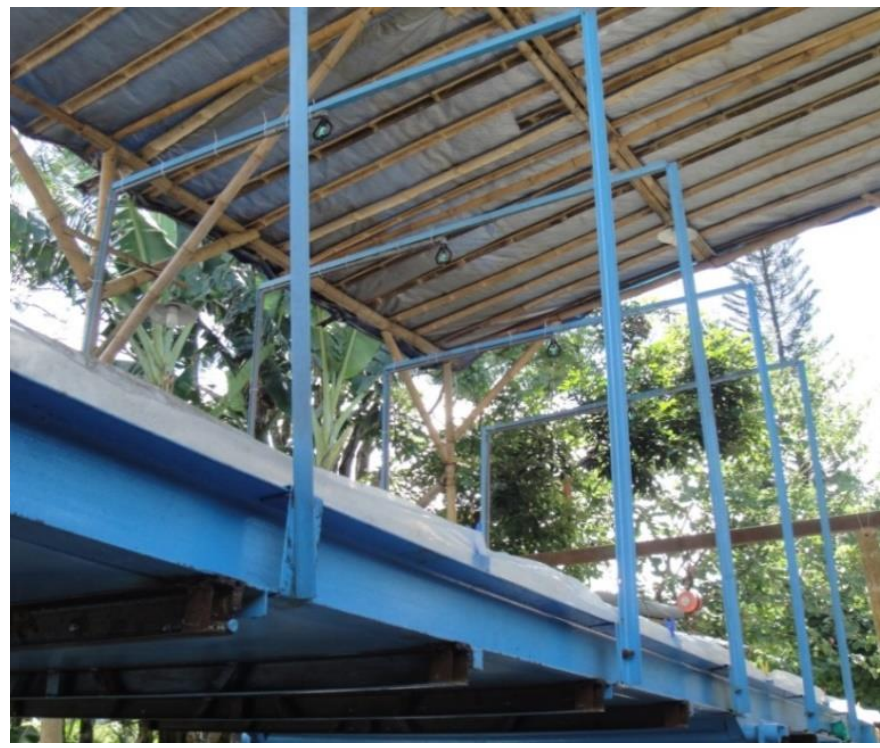

Figure 2. Rainfall simulator with 5 sprinklers and $1 \mathrm{~m}$ distance sprinkler frame.

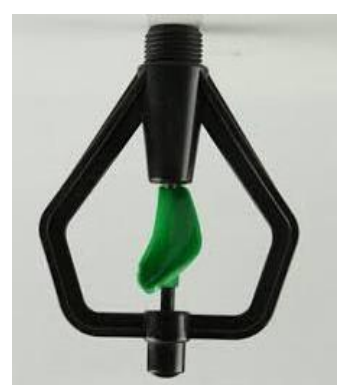

Figure 3. Sprinkler with butterfly type.

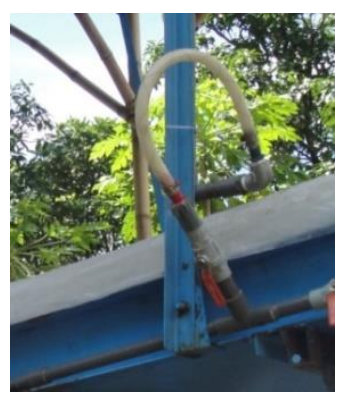

Figure 4. Adjustable sprinkler frame. 
2.2.2. Flow measurement devices preparation. In this research, we measured travel time and discharge data. The travel time data were measured using dye-buoyant-oil tracing method. This method was a synthesised method of the dye tracing and float method. Initially, a problem was appeared when only using the dye method. The raindrop detachment caused the dye was dispersed. At the lower end of the plot, the colour was not visible. The dye was then replaced by glitter powder that was coloured and shiny. However, the glitter powder cannot flow smoothly due to a constraint caused by the joint filler and the configuration of CBP. To solve the problem, oil was applied to the test plot so that the glitter powder can float on oil and reach the lower end. The discharge data was determined by measuring the volume of outflow from gutter every two minutes. The volume in litter were then divided by two minutes.

2.2.3. Study design. The study design was experimental research and correlation analysis. Firstly, we measured the flow velocity on the smooth pavement by applying a set of slope and rainfall intensity. Afterwards, we observed travel time and discharge on four CBP layers with the same set of experimental design. The experimental design was as follows: 1) the slope gradient (S) consisted of $5 \%, 10 \%$ and $15 \%$; 2) the rainfall intensity (I) consisted of $50 \mathrm{mmh}^{-1}, 55 \mathrm{mmh}^{-1}$ and $60 \mathrm{mmh}^{-1}$; and 3) four kinds of CBPs as mentioned above. According to Indonesian Agency of Meteorology Climatology and Geophysics (BMKG), International Civil Aviation Organization (ICAO) and World Meteorological Organization (WMO), the rainfall intensities used in these experiments were categorized as high rainfall intensities. The surface roughness conditions were determined based on the difference of travel time between smooth layer and CBP layer. Then, we calculated roughness coefficient based on travel time formula and roughness coefficient for overland flow developed by [12] and [13].

2.2.4. Izzard's Method, Morgali-Linsley's Method and Sedyowati's Method for calculating travel time. According to a research conducted by [14], Izzard's Travel Time Method was the best established method for estimating the travel time on CBP surfaces besides the method developed by [14], namely Sedyowati Travel Time Method. Whereas the Morgali-Linsley's Equation was developed using kinematic wave analysis and Manning's roughness coefficient that widely used in practice. Those methods have similar formula. They consist of four design parameters, that is $\mathrm{L}$ (length of overland flow or flow path), S (surface slope), i (rainfall intensity), and c (retardance coefficient for Izzard) or $\mathrm{n}$ (Manning roughness coefficient). The formulas are as follows:

1) Izzard's Method: $t_{c}=41.025(0.0007 i+c) L^{0.33} S^{-0.333} i^{-0.667}$

2) Morgali-Linsley's Method: $t_{c}=0.94 L^{0.6} n^{0.6} S^{-0.3} i^{-0.4}$

3) Sedyowati's Travel Time Method: $T_{t}=1.2 .10^{4} \mathrm{Frd}^{0.69} \mathrm{~S}^{-0.59}(I / L)^{-2.99}$; where $\mathrm{Frd}=$ flow retardance factor as a function of $\mathrm{CBP}$ properties, surface slope and raindrop size.

\subsection{Data analysis}

Observation data analysis consisted of statistical analysis and surface roughness condition analysis. Statistical analysis was conducted to know the effects of high rainfall intensity, surface slope and CBP types on surface roughness condition. The analysis consisted of correlation, determination and analysis of variance. Afterwards, the roughness coefficient in each CBP surface was determined using Izzard and Morgali-Linsley Method. The roughness coefficient was modified to be fit for travel time observed data on CBP surfaces and Sedyowati Travel Time Model. The accuration of roughness coefficient selected was analysed using Nash-Sutcliffe efficiency (NSE), mean absolute error (MAE) and root mean square error (RMSE).

\section{Result and Discussion}

\subsection{Roughness observation data on CBP surfaces}


Table 1 shows the observation data of travel time taken from the three CBP surfaces, that is rectangular $\mathrm{CBP} 90^{\circ}$-herringbone pattern (pav1) with openings ratio $(\mathrm{Or}=0.068)$; rectangular $\mathrm{CBP}$ basket-weave pattern (pav2) with $\mathrm{Or}=0.065$; tri-hexagonal $\mathrm{CBP}$ (pav3) with $\mathrm{Or}=0.073$; and hexagonal hollow CBP sand filled (pav4) with $\mathrm{Or}=0.255$. The data were observed in various rainfall intensities and surface slopes as mentioned above.

Table 1. Observation data of travel time and the calculation of the decline of travel time on CBP surface compared with on smooth surface in various surface slope and rainfall intensity.

\begin{tabular}{ccccccccccc}
\hline $\mathrm{S}$ & $\mathrm{I}^{\mathrm{a}}$ & $\begin{array}{c}\mathrm{T}^{\mathrm{b}} \\
\text { smooth }\end{array}$ & $\begin{array}{c}\mathrm{T}^{\mathrm{b}} \\
\text { pav1 }\end{array}$ & $\begin{array}{c}\mathrm{T}^{\mathrm{b}} \\
\text { pav2 }\end{array}$ & $\begin{array}{c}\mathrm{T}^{\mathrm{b}} \\
\text { pav3 }\end{array}$ & $\begin{array}{c}\mathrm{T}^{\mathrm{b}} \\
\text { pav4 }\end{array}$ & $\begin{array}{c}\mathrm{T}_{\mathrm{dec}}{ }^{\mathrm{c}} \\
\text { pav1 }\end{array}$ & $\begin{array}{c}\mathrm{T}_{\text {dec }}{ }^{\mathrm{c}} \\
\text { pav2 }\end{array}$ & $\begin{array}{c}\mathrm{T}_{\text {dec }}{ }^{\mathrm{c}} \\
\text { pav3 }\end{array}$ & $\begin{array}{c}\mathrm{T}_{\text {dec }}{ }^{\mathrm{c}} \\
\text { pav4 }\end{array}$ \\
\hline 0.05 & 50 & 2.05 & 2.68 & 2.65 & 3.02 & 4.28 & 0.63 & 0.60 & 0.97 & 4.28 \\
0.05 & 55 & 1.77 & 2.28 & 2.50 & 2.83 & 3.40 & 0.51 & 0.73 & 1.06 & 3.40 \\
0.05 & 60 & 1.25 & 1.50 & 2.00 & 2.17 & 3.83 & 0.25 & 0.75 & 0.92 & 3.83 \\
0.10 & 50 & 1.75 & 2.67 & 2.40 & 2.67 & 2.78 & 0.92 & 0.65 & 0.92 & 2.78 \\
0.10 & 55 & 1.43 & 2.17 & 2.20 & 2.50 & 1.40 & 0.74 & 0.77 & 1.07 & 1.40 \\
0.10 & 60 & 1.03 & 1.87 & 1.95 & 2.13 & 1.39 & 0.84 & 0.92 & 1.10 & 1.39 \\
0.15 & 50 & 1.38 & 1.92 & 2.10 & 2.63 & 0.95 & 0.54 & 0.72 & 1.25 & 0.95 \\
0.15 & 55 & 0.70 & 1.87 & 1.90 & 2.37 & 1.22 & 1.17 & 1.20 & 1.67 & 1.22 \\
0.15 & 60 & 0.57 & 1.73 & 1.80 & 2.05 & 1.13 & 1.16 & 1.23 & 1.48 & 1.13 \\
\hline
\end{tabular}

a in $\mathrm{mmh}^{-1}$

${ }^{b}$ travel time observational data on smooth and CBP surfaces, in minute

${ }^{\mathrm{c}}$ travel time decline, as results of subtraction between $\mathrm{T}$ pav and $\mathrm{T}$ smooth, in minute

Data in Table 1 were then processed to generate roughness number (RN). Firstly, we calculated travel time decline between travel time on smooth surface and CBP surface. RN was then calculated as a comparison between travel time decline on a CBP surface and travel time of the CBP.

In Figure 5, serial number 1-3 have 5\% slope; serial number 4-6 have 10\% slope; serial number 7-9 have $15 \%$ slope. Serial number 1, 4, 7 have $50 \mathrm{mmh}^{-1}$ rainfall intensities; serial number 2, 5, 8 have 55 $\mathrm{mmh}^{-1}$ rainfall intensity; serial number $3,6,9$ have $60 \mathrm{mmh}^{-1}$ rainfall intensity.

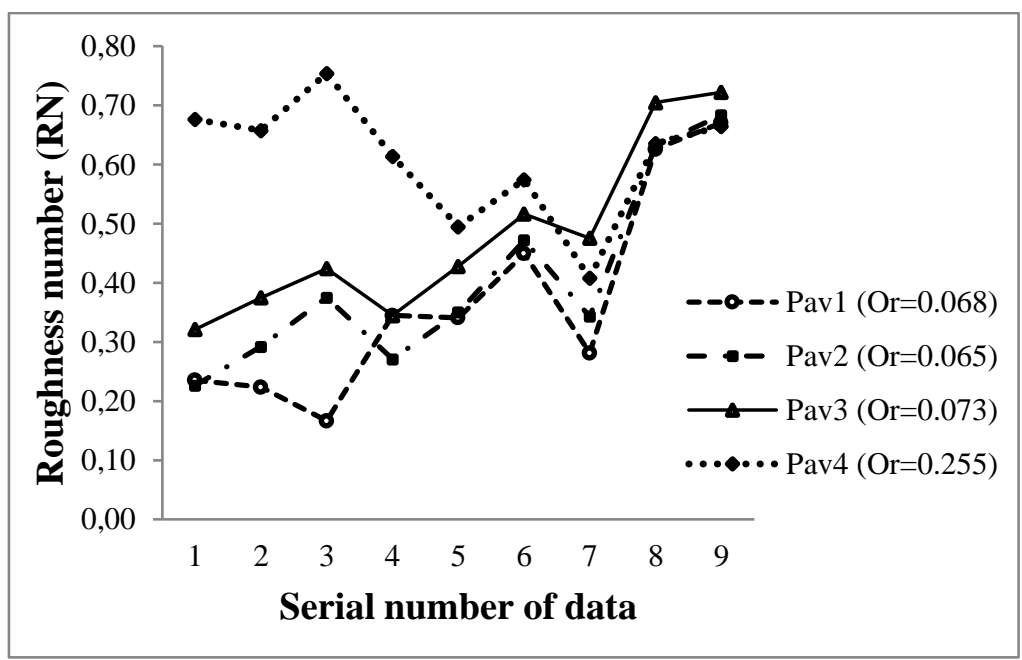

Figure 5. Plotting of roughness number (RN) data in the all CBP surfaces in various surface slope and rainfall intensity 
Figure 5 describes that the increase in rainfall intensity led to the increase in roughness number. According to [5] and [15], the greater rainfall intensity will lead to a greater raindrop splash. It also can be seen that the roughness number increased with an increase in surface slope. All CBP indicated the similar trend. This result supported a study conducted by Pagliara [4].

Contrastingly, pav1 particularly at 5\% surface slope had different trend. It can be explained that in saturation and low slope condition, there was no more water penetration in pav1 (rectangular herringbone CBP), even under high rainfall intensity. The pavers gap in pav1 did not form a flow path that could maximized the water penetration [1].

Pav4 indicated the greater mean roughness number with different trend particularly at $5 \%$ slope. However, at $10 \%$ and $15 \%$ slopes, despite having the largest openings ratio (Or), pav4 shows the same roughness value as pav1 and pav2, and even lower than pav3. Pav1 had smallest mean roughness number. At $5 \%$ slope, pav1 and pav2 showed significant differences in roughness number. However, at $10 \%$ and $15 \%$ slopes there was no significant difference in roughness number. The type and shape of paving blocks showed a significant effect on roughness. Pav3 with more cavities on its surface provides a higher roughness value compared with rectangular shapes. This is in accordance with Darboux's result [6]. While the difference in arrangement of rectangular paving block only gave significant effect at the mild slope. In this study, the CBP arrangement consisted of herringbone and basket-weave, and the basket-weave pattern was better in generating the roughness condition than herringbone.

\subsection{Correlation between roughness condition and the design parameters}

Correlation analysis was performed using MS Excel. Correlation coefficient (R) resulted from the Excel calculation was then squared to obtain determination coefficient (R2). Those coefficients were used to identify the effects of the all design parameters on roughness number. The design parameters consisted of surface slope and rainfall intensity.

According to Figure 5, the trend of pav4 significantly differed with the others, therefore, the correlation analysis neglected the pav4 data. Table 2 presents the correlation and determination coefficient between surface slope (S), rainfall intensity (I) and roughness number (RN). The correlation between roughness number and surface slope $(\mathrm{R}=71 \%)$ was greater than roughness number and rainfall intensity $(\mathrm{R}=47 \%)$. Surface slope affected roughness number up to $51 \%$, whereas rainfall intensity up to $22 \%$. Those results described that surface slope was the major factor that can retard the flow velocity, particularly on steep slope. The increase in surface slope will significantly increase the roughness number. This was in accordance with Figure 5 above and research results found by Pagliara [4].

Table 2. Correlation and determination coefficients between surface slope, rainfall intensity and roughness number

\begin{tabular}{lcccc}
\hline \multirow{2}{*}{ Parameter } & \multicolumn{3}{c}{$\mathrm{R}$} & \multirow{2}{*}{$\mathrm{R}^{2}$} \\
\cline { 2 - 4 } & $\mathrm{RN}$ & $\mathrm{S}$ & $\mathrm{I}$ & \\
\hline $\mathrm{RN}$ & 1.00 & & & 1.00 \\
$\mathrm{~S}$ & 0.71 & 1.00 & & 0.51 \\
$\mathrm{I}$ & 0.47 & 0.00 & 1.00 & 0.22 \\
\hline
\end{tabular}

Figure 6 shows that for all observed data with rain intensity $50 \mathrm{mmh}-1,55 \mathrm{mmh}-1$, and $60 \mathrm{mmh}-1$ the relationship between roughness number and surface slope followed polynomial function, $R N=$ 16.507. $S^{2}-0.5253 . S+0.2782$ with determination coefficient 0.5236 . Figure 7 describes the scatter 
diagram for each CBP surfaces. It can be seen that in pav1 surface slope had the largest influence to the roughness number $\left(R^{2}=0.67\right)$, then followed by pav3 $\left(R^{2}=0.66\right)$ and pav2 $\left(R^{2}=0.51\right)$.

Pav2 had the smallest effect of surface slope due to the flow path formed by the paving block arrangement causing the water penetration was more affected by the rainfall intensity than the surface slope. These results supported the results of Collins [1] and Sedyowati [15]. While on pav1 and pav3 the arrangement pattern did not cause the occurrence of a straight flow path that led to water penetration. Roughness factor was more influenced by CBP surface configuration and surface slope.

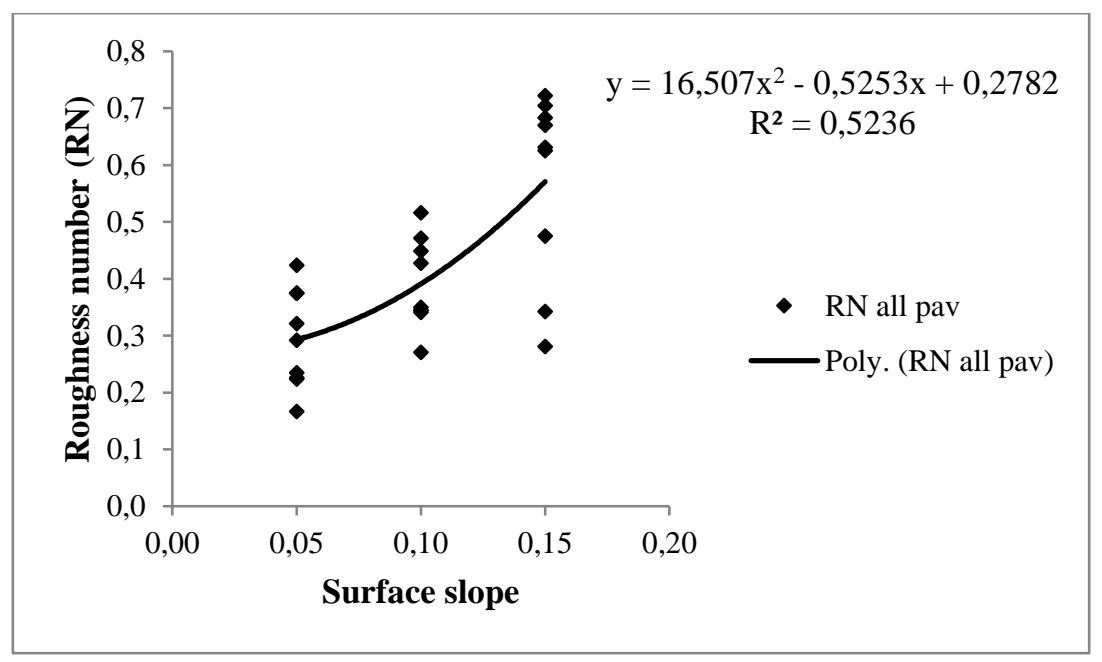

Figure 6. Relationship between surface slope and roughness number in all various $\mathrm{CBP}$ and rainfall intensity.

Figure 7 also indicates that in each CBP surface the greatest correlation between roughness number and surface slope followed a polynomial function. Pav3 indicated the greatest roughness number. Pav2 and pav3 showed similar trend. This was due to the surface configuration of pav3 more varied in the presence of more cavities, and the greater opening ratio than pav1 and pav2. It significantly affected on surface roughness factors, and supported the conclusions of Darboux [6] and Medeiros [9].

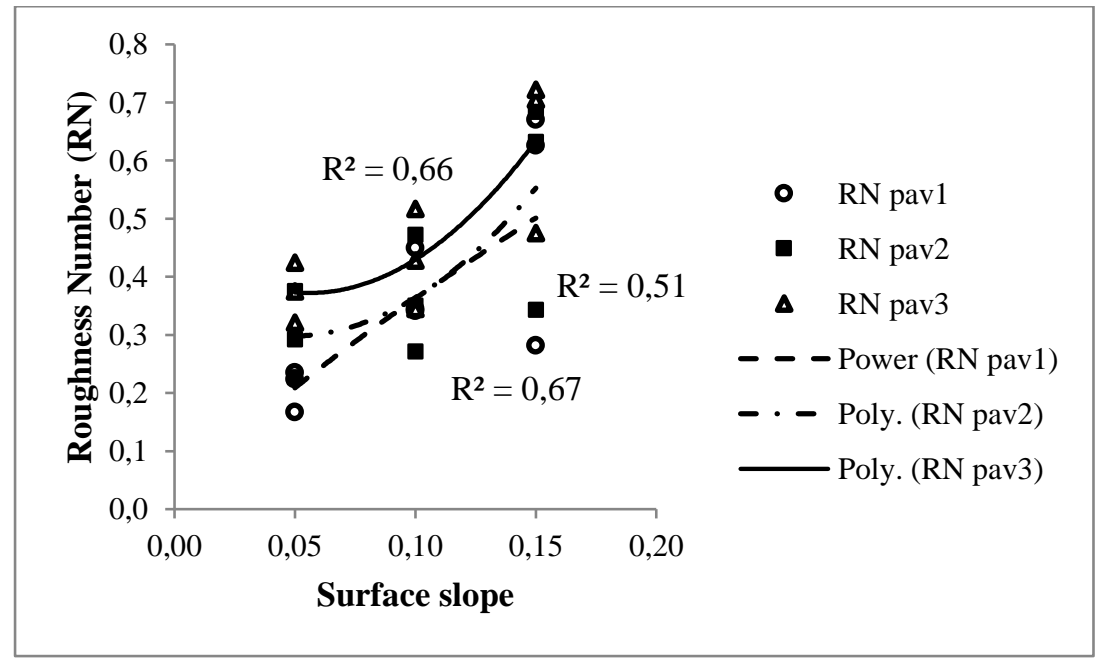

Figure 7. Relationship between surface slope and roughness number on pav1, pav2 and pav3 in various rainfall intensity. 
Figure 8 presents the relationship between roughness number and rainfall intensity in various surface slope and the three types of CBP surfaces. It can be seen that rainfall intensity moderately influence roughness number $\left(\mathrm{R}^{2}=0.23\right)$ and the relationship was also expressed by a polynomial function, $R N=-0.0014 . I^{2}+0.1701 . I-4.7361$.

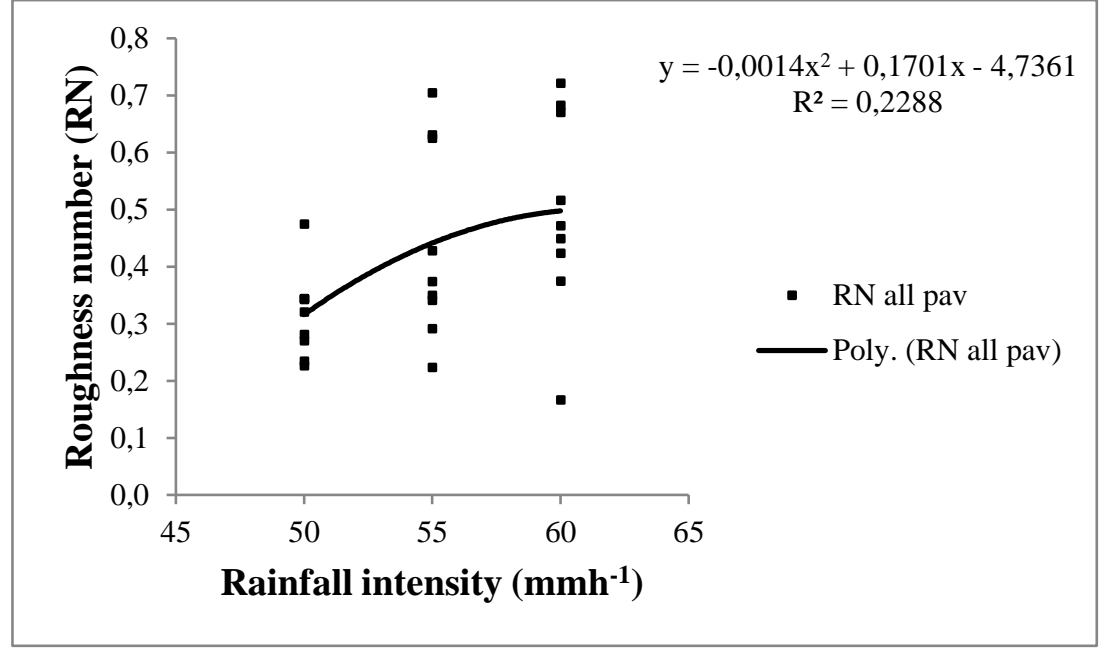

Figure 8. Relationship between rainfall intensity and roughness number in all various CBP and surface slope.

In contrast to Figure 6, in Figure 9 pav2 shows greatest determination coefficient $(\mathrm{R} 2=0.46)$, and the lowest was pav1. The pattern of rectangular herringbone (pav1) did not allow more water penetration, therefore, rainfall intensity did not significantly contribute on the roughness condition. The roughness condition was more affected by surface slope. Whereas in pav2 there were more water penetration caused by the flow path formation as mentioned by Collins [1] and the raindrop splash effects as stated by Engman [5] and Jomaa [8]. More water penetration affected on the water depth. The decrease in water depth led to the increase in roughness condition. This result agreed to Boundary Layer Theory developed by L. Prandtl (1904) in [16], and research result by Mugler [10] and Smith [11].

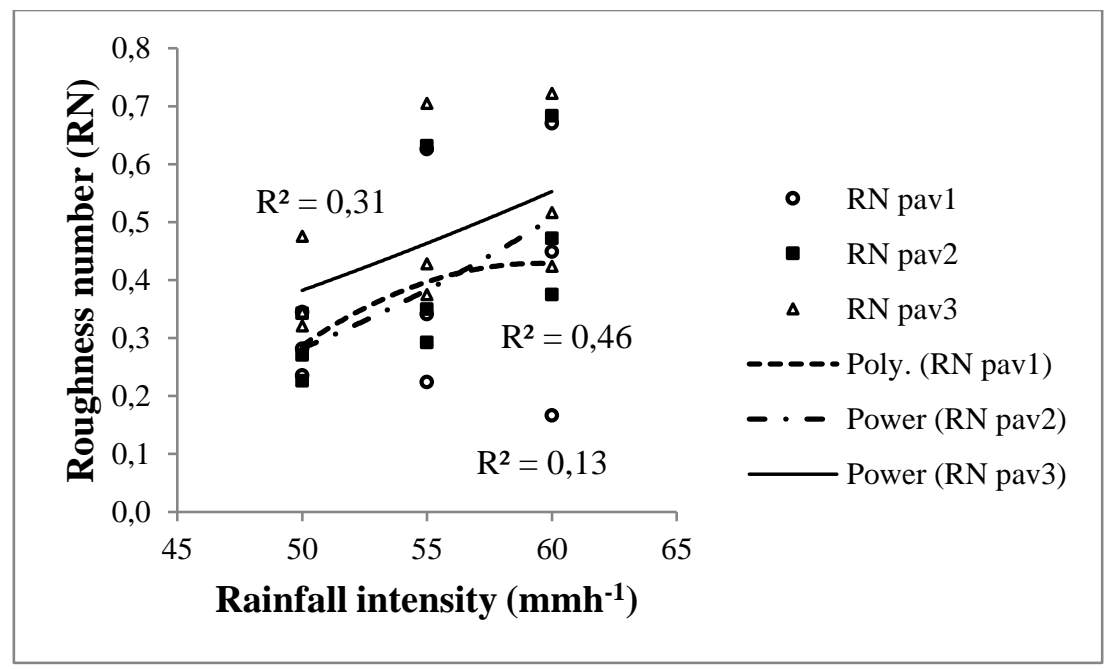

Figure 9. Relationship between rainfall intensity and roughness number on pav1, pav2 and pav3 in various surface slope. 


\subsection{Roughness coefficient analysis on CBP surfaces}

Comparison between the observational data and simulation data calculated by Izzard's method resulted Izzard roughness coefficient (c) for CBP overland flow, as follows: pav1 had $\mathrm{c}=0.0125$; pav2 had c $=0.013$; and pav3 had $\mathrm{c}=0.015$. The NSE, MAE and RMSE respectively were $65 \%, 21 \%$, $30 \%$. Whereas comparison between simulation data generated by Izzard's method (with that Izzard coefficient mentioned above) and Sedyowati's Model resulted NSE, MAE and RMSE respectively were $75 \%, 20 \%, 23 \%$. It indicated that the observational data had wider range than the simulation data.

Comparison between the observational data and simulation data calculated by Kinematic Wave method developed by Morgali-Linsley resulted Manning roughness coefficient (n) for CBP overland flow, as follows: pav1 had $\mathrm{n}=0.09$; pav2 had $\mathrm{n}=0.1$; and pav3 had $\mathrm{n}=0.012$. The NSE, MAE and RMSE respectively were $66 \%, 21 \%, 30 \%$, almost the same as the Izzard Method. However, when Kinematic Wave method (with that Manning coefficient mentioned above) compared with Sedyowati's Model, the accuration value was lower than the Izzard Method. The NSE, MAE and RMSE respectively were $64 \%, 23 \%, 27 \%$. These results supported the research results of Sedyowati [14].

\section{Conclusions}

The widespread usages of CBP particularly used as road need more attention in order to optimize the CBP functions. This study concluded that hydraulic performance of surface runoff in the CBP layer was more influenced by the surface roughness condition. The roughness condition was very sensitive to the change in surface configuration of the CBP, even only a little change. The rainfall intensities performed a little influence on the roughness condition (22\%), however surface slope had significant impact $(51 \%)$. The relationship between rainfall intensity, surface slope and roughness number followed polynomial functions. The equalization results of CBP surface roughness to Izzard coefficient (c) and Manning coefficient (n) are as follows: pav1 (rectangular CBP with herringbone pattern) had $\mathrm{c}=0.0125$ and $\mathrm{n}=0.99$; pav2 (rectangular CBP with basket-weave pattern) had $\mathrm{c}=0.013$ and $\mathrm{n}=0.1$; and pav3 (tri-hexagonal CBP) had $\mathrm{c}=0.015$ and $\mathrm{n}=0.012$.

A further study is required to determine the quality of CBP that can be applied on steep slopes, as well as the strength of $\mathrm{CBP}$ to withstand the raindrop detachment resulted from the high rainfall intensity.

\section{Acknowledgements}

We would like to thank to the people who have contributed in conducting this research, especially the students of Civil Engineering Department, University of Merdeka Malang. This research was financially supported by The Ministry of Research, Technology and Higher Education, Republic of Indonesia, through research grant namely Penelitian Produk Terapan (PPT) 2017.

\section{References}

[1] K. A. Collins, W. F. Hunt, and J. M. Hathaway, "Hydrologic comparison of four types of permeable pavement and standard asphalt in eastern North Carolina," J. Hydrol. Eng., vol. 13, no. 12, pp. 1146-1157, 2008.

[2] L. Sedyowati, S. Suhardjono, E. Suhartanto, and M. Sholichin, "Runoff velocity behaviour on smooth pavement and paving blocks surfaces measured by a tilted plot," J. Water Land Dev., vol. 33, no. 1, pp. 149-156, 2017.

[3] R. E. Horton, "The role of infiltration in the hydrologic cycle," Eos Trans. Am. Geophys. Union, vol. 14, no. 1, pp. 446-460, 1933.

[4] S. Pagliara, R. Das, and I. Carnacina, "Flow resistance in large-scale roughness condition," Can. J. Civ. Eng., vol. 35, no. 11, pp. 1285-1293, 2008. 
[5] E. T. Engman, "Roughness coefficients for routing surface runoff," J. Irrig. Drain. Eng., vol. 112, no. 1, pp. 39-53, 1986.

[6] F. Darboux, P. Davy, C. Gascuel-Odoux, and C. Huang, "Evolution of soil surface roughness and flowpath connectivity in overland flow experiments," Catena, vol. 46, no. 2, pp. 125 $139,2002$.

[7] J. U. Eitel, C. J. Williams, L. A. Vierling, O. Z. Al-Hamdan, and F. B. Pierson, "Suitability of terrestrial laser scanning for studying surface roughness effects on concentrated flow erosion processes in rangelands," Catena, vol. 87, no. 3, pp. 398-407, 2011.

[8] S. Jomaa et al., "Rain splash soil erosion estimation in the presence of rock fragments," Catena, vol. 92, pp. 38-48, 2012.

[9] S. C. Medeiros, S. C. Hagen, and J. F. Weishampel, "Comparison of floodplain surface roughness parameters derived from land cover data and field measurements," J. Hydrol., vol. 452, pp. 139-149, 2012.

[10] C. Mügler et al., "Comparison of roughness models to simulate overland flow and tracer transport experiments under simulated rainfall at plot scale," J. Hydrol., vol. 402, no. 1, pp. $25-40,2011$.

[11] M. W. Smith, N. J. Cox, and L. J. Bracken, "Terrestrial laser scanning soil surfaces: a field methodology to examine soil surface roughness and overland flow hydraulics," Hydrol. Process., vol. 25, no. 6, pp. 842-860, 2011.

[12] C. F. Izzard and W. I. Hicks, "Hydraulics of runoff from developed surfaces," in Highway Research Board Proceedings, 1947, vol. 26.

[13] J. R. Morgali and R. K. Linsley, "Computer analysis of overland flow," J. Hydraul. Div., vol. 91, no. 3, pp. 81-100, 1965.

[14] L. Sedyowati, Model Waktu Aliran Berdasarkan Model Faktor Retardasi Aliran Pada Permukaan Paving Blok. Digital Library University of Brawijaya, 2017.

[15] L. Sedyowati and E. I. Susanti, "Effects of Concrete Block Pavement on Flow Retardation Factor," J. Appl. Eng. Sci., vol. 7, no. 1, pp. 28-36, 2017. 